\title{
Comparing Regional Human Development using Global Frontier Difference Indices
}

\author{
Tom Van Puyenbroeck \\ Nicky Rogge \\ Faculty of Economics and Business, KU Leuven \\ Warmoesberg 26, 1000 Brussels, Belgium
}

January 2018

\begin{abstract}
It is well-known that composite indicator construction relies on several intermediate modelling steps and that, as a result, one should be cautious about the exact rankings of observations on the basis of specific composite index values. One way to deal with this concern rests on comparing groups rather than individual observations, which has e.g. been advocated for the well-known Human Development Index. Data Envelopment Analysis, which has become quite popular for composite indicator construction, also provides some tools to assess such intergroup differences. We here focus on the Global Frontier Difference index as introduced by Asmild and Tan (2007), and use some variants of this index to study inter-regional differences in human development performance.
\end{abstract}

Keywords: Composite indicator; Benefit of the Doubt; Data Envelopment Analysis, Human Development Index; Inter-regional differences; Global Frontier Difference index 


\section{Introduction}

Of all composite indicators that are currently in use, the United Nations Development Programme's (UNDP) Human Development Index is not only one of the oldest, but it also figures prominently in a large number of scientific publications. Next to its frequent substantive use, it has been subject to critical writings on virtually all aspects that typically constitute the major modelling options in composite indicator methodology (see Hirai, 2017, for a recent and extensive review). Referring to Nardo et al. (2005), these options pertain to the choice of constituent data (indicators as well as the level at which these are measured), the way of rendering these building blocks commensurable, and the weighting and aggregation method used when combining these data. Alternative constituent indicators have replaced or have been added to the original GDP/Education/Life expectancy set (e.g. to better grasp dynamics as in Hou et al., 2015, or to add more dimensions of human development, e.g. Morse, 2003). Its original application to country data has been extended to the regional, municipal and even household level (e.g. Hardeman \& Dijkstra, 2014; Martin \& Mendoza, 2013; Van Puyenbroeck, 2017; Harttgen \& Klasen, 2012), as well as to long-term analysis (Crafts, 2002; Conte et al., 2007). Several alternative weighting techniques (ranging from data-driven methods such as PCA, e.g. Lai, 2003, to weighting based on opinion surveys as in Chowdhury and Squire, 2006) and aggregation procedures (including e.g. the non-compensatory Borda rule, see Qizilbash, 1997) have equally been employed. In point of fact, even when confined to the specific approach we use in this paper, viz. the construction of human development indices based on data envelopment analysis (see below), the literature is already quite extended (for a literature survey, see Mariano et al. 2015).

The use of so many different alternatives instigates the need for robustness and sensitivity assessment of the HDI's resulting country rankings. Such analyses have e.g. been provided by Cherchye et al. (2008), Aguña and Kovecevic (2010), Permanyer (2011), and Foster et al. (2013). Relatedly, because sensitivity to modelling options might induce 'league tables' with only marginal (and methodologically fragile) differences between some countries, some authors have advocated to consider (comparisons between) country categories rather than between individual countries (e.g. Cherchye et al. 2008, Høyland et al., 2012).

In this respect, it should be recalled that the UNDP also use some country classifications in its Human Development Reports. Its "human development classification" is based on a country's HDI-value, categorizing it as either being in a state of 'very high' (HDI-value of 0.8 or more), 'high' $(0.7 \leq$ HDI-value < 0.8), 'medium' $(0.55 \leq$ HDI-value $<0.7)$ or 'low' human 
development (HDI-value less than 0.55). This fixed, threshold nature allows for an intertemporal follow-up of the worldwide evolution of human development, as is for example done in UNDP (2015, p. 55), where it is stated that the number of countries in the very high human development classification rose from 12 to 46 between 1990 and 2014, while during the same period the number of countries in the low human development classification fell from 62 to 43.

Evidently, such statements are still contingent on the specific HDI construction and human development classification method used. As for the latter, it should be recalled that some authors have presented alternative, data-driven country groupings (e.g. Noorbakhsh, 1998; Aguña \& Kovecevic, 2010; Bougnol et al., 2010). Furthermore, and importantly, in many cross-section and intertemporal breakdowns the UNDP itself simultaneously makes use of an alternative way of grouping countries, viz. on the basis of regional classifications. Specifically, within the group of developing countries it distinguishes between the Arab States (20 countries/territories), East Asia and the Pacific (24), Europe and Central Asia (17), Latin America and the Carribean (33), South Asia (9) and Sub-Saharan Africa (46), while the (32) developed OECD-countries are also considered as a separate group. ${ }^{1}$

Figure 1 show the evolution and cross-sectional differences in human development (indices) according to this regional breakdown, according to reported average HDI values. Progress is discernible everywhere, but so are the sometimes large gaps between the different regions, even when the least developed regions seems to catch up slightly over the most recent period. Simultaneously, one observes that some regions are sometimes actually quite close in terms of their (average) HDI-value, and some concomitant regional re-rankings over the period considered.

\footnotetext{
${ }^{1}$ Chile (ranked 38 in the 2016 Human Development Report), Mexico (71) and Turkey (77), while being OECDmembers, are considered developing countries in the Human Development reports (see HDR 2016, p. 194). In our analysis below, we will accordingly exclude these countries from our OECD country group, so comprising 32 of its 35 members. Chile and Mexico are thus part of the Latin America group, while Turkey is member of the "Europe and Central Asia" group of (developing) countries. Note that the UNDP defines still other groups (the "Least-developed" and "small island developing states") which partly overlap with other (regional) groups and that we do not use in the current paper.
} 
Figure 1: Regional breakdown of HDI: period 1990-2015

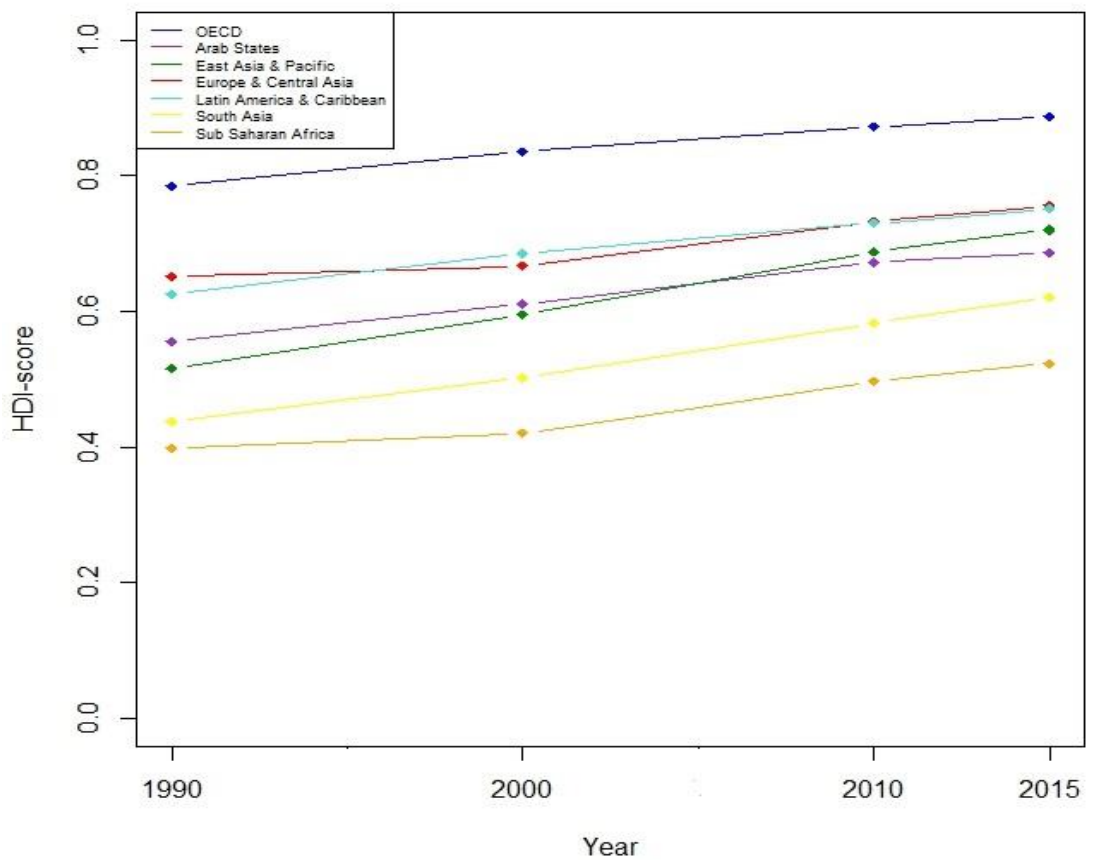

In this paper we also examine human development differences between these regional country groups. However, rather than calculating and comparing average regional HDI-scores, we employ data envelopment analysis (DEA hereafter) to examine the extent of global differences between regional human development best practice frontiers. The application of data envelopment analysis, frequently referred to as 'benefit-of-the-doubt' (BoD) weighting in the specific context of composite indicator construction, to human development indices dates back at least to Mahlberg and Obersteiner (2001), and Despotis (2005a, 2005b). The well-known essence of this approach, as briefly recaptured in a formal fashion in the following section, is that weights are country-specific and endogenous, i.e. chosen such that a country's index value is maximized, with the important proviso that these weights are applied to other countries to determine the score of the particular country under investigation. The latter feature instigates a rather compelling case for being outperformed in those cases in which one or more other countries have a demonstrably higher aggregate score, notably if the most favorable weights of the analyzed country itself are applied to aggregate those other countries' constituent subindicators. Indeed, the determination of best practice observations (i.e. countries that are not demonstrably outperformed by others using the approach just sketched) is an important feature of DEA.

Evidently, using DEA implies a departure from the specific weights as used in the actual HDI, which leads to different (i.e. higher) country-specific scores and could eventually thus also 
entail that group level comparisons are affected. This is (self-)evident if one opts for a reexamination of countries with the aforementioned human development classification method: given the generous "benefit-of-the-doubt" weighting method, even when (slightly) moderated by appending the additional weight restrictions that we document in the next section, the number of 'very highly' developed countries (i.e., HDI-score of 0.8 or more) would be no less than 110, and only 9 countries would be situated in the low human development category (HDIscore $<0.55)$ when using 2015 data. Of course, this specific example basically just illustrates the general consequences of using DEA, and, notably because it allows for changes in weights without accordingly changing the original UNDP threshold values, few substantive conclusions should be drawn from it. But the more general question of course remains whether and to what extent reverting to a different index construction method, such as e.g. DEA, has an impact on intergroup comparisons.

In this respect, it is well-known that one of the very first papers on DEA already addressed the problem of accounting for any systematic intergroup differences (Charnes, Cooper $\&$ Rhodes, 1981). Essentially, such differences are detected by comparing an observation's performance relative to peers belonging to its own group, i.e. relative to the group's best-practice frontier, with its performance relative to a pooled or so-called metafrontier (after O'Donnell et al., 2008) constituted by enveloping all observations. Recent applications of this approach to composite indicators, which we will also briefly illustrate below for our human development case, are provided by Karagiannis and Karagiannis (2018).

The main focus of this paper is, however, on an alternative approach for assessing intergroup differences, viz. the so-called Global Frontier Difference index of Asmild (2015) (see also Asmild \& Tam, 2007), which does not necessitate the construction of a pooled metafrontier. We present a chained version, its decomposition, and an inter-temporal version of this index below, and apply it to similar regional categories as those appearing in Figure 1, thereby complementing the recent introduction of the metafrontier approach to intergroup comparative analysis in a BoD setting by Karagiannis and Karagiannis (2018). However, contrary to Karagiannis and Karagiannis (2018), we opt for a robust version of DEA, so as to deal with potential biases in BoD-based composite HDI estimates, originating either from unequally sized country groups or from the potential presence of country with outlying/atypical human development data. 
The rest of this paper unfolds as follows. After a concise discussion in section 2 of our data and BoD-model, we turn to a discussion of the Global Frontier Difference index in section 3. Section 4 applies these to HDI data for the years 2010 and 2015. Section 5 concludes.

\section{The basic model and data}

The HDI combines country data on life expectancy, knowledge (as measured by expected and mean years of schooling) and gross national income per capita, albeit that a few data transformations are performed before these original data are aggregated into a final country HDI-value. We refer to UNDP (2016b) for further details on the exact way in which original data are treated, and here only point out that the HDI, in its current version, is an unweighted geometric mean of three constituent indices, viz. a health index based on life expectancy, an income index based on a country's gross national income per capita, and an education index based on expected and mean years of schooling. All three are called indices since original data have been normalized so as to make them dimension-free (hence, commensurable), taking on values between 0 and 1 (with higher values indicating better performances). As we want to focus on benefit-of-the-doubt weighting in this paper, we opt for a ceteris paribus analysis and do not alter any of the methodological building blocks of the original HDI-construction method except for the weighting and aggregation method itself. Put otherwise, in our ensuing analysis we take the health, income and education index values as our constituent data, as calculated on the basis of the data that can be found on the official HDI website (see, http://hdr.undp.org/en/composite/HDI) or in the official HDR-reports (e.g. UNDP, 2016a).

The benefit-of-the-doubt weighting model we employ is a fairly standard one and is developed along similar lines as e.g. in Cherchye et al. (2007). Formally, let $Y_{i j}$ be the value of the $i$-th constituent index value of country $j(j=1, . ., n)$. In our application $i=1, . ., 3$ and $n$ equals 181 . The composite indicator value for the evaluated country $o$ is the value of the objective function of the following program: 


$$
\theta_{o}=\max _{w_{i 0}} \frac{\sum_{i=1}^{I} w_{i 0} Y_{i 0}}{\max _{Y_{i j}} \sum_{i=1}^{I} w_{i 0} Y_{i j}}=\max _{w_{i 0}} \min _{Y_{i j}}\left(\frac{\sum_{i=1}^{I} w_{i 0} Y_{i 0}}{\sum_{i=1}^{I} w_{i 0} Y_{i j}}\right)
$$

s.t.

$$
\begin{array}{ll}
\sum_{i=1}^{I} w_{i 0} Y_{i j} \leq 1, & j=1, \ldots, n \\
w_{i 0} \geq 0, & i=1, \ldots, I
\end{array}
$$

The left-hand side of the objective function clearly shows that one looks for weights that maximize a country's relative aggregate performance, whereby relative we mean that one looks among the other ('peer') countries whether there exists one or more observations that would yield a higher aggregate score, yet applying country $o$ 's most favorable weights. The constraints $\sum_{i=1}^{I} w_{i j} Y_{i j} \leq 1, j=1, \ldots, n$ can be regarded as normalization or comparison constraints, ensuring that the (denominator of the) objective function is bounded. Thus, in any optimal solution to the above program, at least one of these normalization constraints is binding, implying a vanishing denominator, so that the objective function de facto boils down to the weighted sum form $\theta_{o}=\sum_{i=1}^{I} w_{i o} Y_{i o}$.

It should be noted that the only restriction on weights in the above program is that they should be non-negative. Specifically within the context of constructing composite indicators, the possibility that some countries' objective value is maximized when assigning zero weight to one or more indicators is often taken to go against the idea of combining multiple relevant dimensions that are taken to pertain to the underlying phenomenon that is assessed. For instance, it is reasonable that one would like to avoid that a country, due to otherwise unconstrained benefit-of-the-doubt weighting, is associated with an 'optimal' human development aggregate in which, say, only the income index is effectively retained, while the other two weights are set at zero. This scenario is usually avoided by adding additional restrictions on the range of allowable weights. We refer to Cherchye et al. (2007) for a more detailed discussion. In all our applications below we mildly restrict this range by ensuring that any of the three (weighted) index values should account for at least $5 \%$ of a country's aggregate composite indicator value, i.e. we require that 


$$
0.05 \leq \frac{w_{k 0} Y_{k 0}}{\sum_{i=1}^{I} w_{i 0} Y_{i 0}}, \quad i=1, . ., 3
$$

This model is of course not free of criticism. For example, in the above formulation the benefitof-the-doubt-weights are, by construction, endogenous and unit-specific. Thus, when the composite indicator value of one unit is constructed using a different set of aggregating weights than used for those of other assessed units, this implies an ambiguous ranking of units on the basis of their optimal benefit-of-the-doubt scores. Also, the model seeks as to maximize the composite value of an assessed unit. Essentially, this means that good relative performance is rewarded, whereas the impact of a sub-indicator performance that is relatively inferior in comparison with other observations will be minimized. One could object to this perspective by taking the opposite view that in fact relatively more attention should be devoted to subindicators in which improvement is demonstrably possible, and less to performance dimensions in which one is already showing a (relatively) quite good result. Next, considering as its objective a weighted sum of sub-indicators, this model implies complete and constant substitutability among the various components, a feature that may be highly unwarranted in the composite indicator setting. We refer to Mariano et al., 2015 for references on variant BoDmodels that have addressed such problems, notably in the context of assessing human development. While all such modifications can be applied to our framework fairly straightforwardly, we here use the above rather basic BoD-model to focus on the question of inter-group comparisons.

Still, as our concern with comparing group performances (rather than individual country performances/rankings) is essentially given in by a concern for sufficient robustness, there are two problems of the above model that we explicitly deal with. A first issue is that country groups are of different size, which may cause a bias in the estimation of the composite HDIvalues for the individual countries as well as for the country groups (so-called group size bias, see Staat, 2001, 2006), a concern that we will explain further in the next section. A second problem is that the position and the shape of the estimated best practice frontier and, hence, the estimations of the composite HDI-values are sensitive to countries with human development data that are atypical/outlying (which would constitute extreme benchmarks/best 'practices', showing up in one or more of the $j=1, . ., n$ comparison constraints and thus potentially having a large impact on the eventual composite HDI-values). Both issues are related to the deterministic nature and the relative perspective taken in DEA and BoD. To mitigate the impact of different group sizes and countries with atypical/outlying human development data (if 
present in the sample) in the estimations of the HDI-scores, we apply a robust version of the benefit of the doubt program as in (1)-(2) that is inspired by the robust order- $m$ DEA-model of Cazals, Florens and Simar (2002) (see also Daraio \& Simar (2007) for a more detailed explanation of the method as well as a discussion of attractive statistical properties that carry over to our setting). The essential idea of this approach is to develop a robust specification of the best practice frontier under a simple bootstrapping framework in which $B$ runs $(b=1, \ldots, B)$ are performed (with $B$ a large number, in casu 2,500 runs), in each of which a sub sample of only $m$ countries (randomly and i.i.d. drawn) are used in the specification of the best practice frontier. ${ }^{2}$ The robust versions of BoD-weighted HDI-values are computed as the arithmetic average of the estimations obtained in these $B$ runs. As countries with atypical and/or outlying human development data do not form part of the sub sample in every draw, the impact of such countries on the estimations of the HDI-values is effectively mitigated. Moreover, by setting the $m$-value equal for all country groups (here, $m=5$ ), country composite HDI-scores are always compared to the same number of peers (irrespective the country group of reference). ${ }^{3}$ This neutralizes the issue of size bias due to unequal country group sizes.

To end this section, we recall BoD's crucial underlying idea that, whether one opts for a deterministic or Monte Carlo approach, a country's performance is always assessed relatively to a set of observations that is taken to collect that country's peers. It is exactly that feature which essentially underlies the idea of accounting for possible group differences, as we discuss in the next section.

\footnotetext{
${ }^{2}$ As pointed out by a referee, another approach to estimate CIs that are robust to the presence of countries with (strongly) atypical and/or outlying human development data is the super efficiency model as presented in the DEA-literature by Banker and Gifford (1988) and Andersen and Petersen (1993). In particular, the superefficiency model could be used to identify and screen out countries with outlying and/or atypical data (e.g., due to gross data errors) so as to obtain more reliable estimates of CIs after removing those countries. Though there are some similarities between this super efficiency approach and the robust order-m approach, in the sense that both aim at estimating 'robust' CIs, there are notable differences as well. Firstly, the super efficiency approach drops countries suspected of having outlying/atypical data from the sample set, whereas the robust order-m method does not and only mitigates the effect of these countries in the estimations of the CIs. Secondly, the super efficiency method does not solve the issue of group size bias whereas the robust order-m method does enable a correction for different sizes of country groups by setting the $m$-value equal for all country groups (here, $m=5$ ). In view of the latter, and given our specific application, we opted for using the robust order-m method.

${ }^{3}$ For a more comprehensive discussion of the role of the parameter $m$, see Cazals et al. (2002) and Daraio and Simar (2007).
} 


\section{Estimating global group differences}

We now consider the case in which observations belong to $G$ (mutually exclusive) groups $g_{1}, g_{2}, \ldots, g_{G}$ (where, slightly abusing notation, the number of observations belonging to a group $g_{j}$ will be denoted as $\left.\# g_{j}\right)$. In our empirical setting, these groups are the seven regions depicted in Figure 1. The idea to recalculate HDI-values using the above DEA-model as in (1) together with the additional weight restriction as in (2), but focusing on comparisons within a specific region only, was already taken up by Despotis (2005b). Evidently, such exercises generate region-specific benchmarks, or, equivalently, region-specific best-practice frontiers, and accordingly generate intra-regionally determined country composite indicator values.

A natural question in such a setting then relates to possible inter-group differences. As stated in the introduction, one way to assess such differences rests on the Charnes et al. (1981) 'program efficiency' idea of comparing a country's results as obtained by an intra-group benchmarking exercise with those obtained from a similar analysis where all observations (belonging to the $G$ groups) are pooled and a metafrontier is constructed. The ratio between a country's pooled score and its within-group score then reveals, for that specific country, the effect of belonging to a specific group.

Let us provide a brief example: when one applies the traditional (non-robust) version of the BoD-model as in (1) restricted with the additional weight restrictions as specified in (2) to the 2015 health, income and education index values of the 46 Sub-Saharan African countries only, both the Seychelles and Mauritius obtain the maximum score, and therefore constitute the benchmarks of all other countries belonging to this region. On the other hand, if all countries (including those of other regions) are pooled, both countries obtain a composite human development indicator value of 0.85 and 0.86 respectively. Similarly, the Central African Republic obtains a value of 0.47 when compared to all countries in the world-wide sample, and a score of 0.55 when compared to other Sub-Saharan countries only. In these three cases, the group effect is thus such that the DEA-based composite indicator must be adjusted with a factor of about 0.85 if one compares within Sub-Saharan African group results with the world-wide sample.

When the part of the regional frontier against which a country is assessed coincides with or is close to the full sample frontier, one expects a ratio value equal to or close to 1 . This is e.g. the case for Qatar (obtaining the maximum score within the group of Arab States, and a value of 0.99 when compared with all other countries) or the United Arab Emirates (with a within group 
value of 0.98 and a pooled value of 0.97 ) and, notably, for all OECD countries, which in fact all have a pooled frontier/own group ratio value exactly equal to one. The latter clearly demonstrates that the OECD best-practice frontier in fact constitutes a large part (and, in point of fact, for our particular data set fully coincides with) the best-practice frontier of the full sample.

It should be noted that the above within and between group comparisons are always related to one specific country at the time. However, Karagiannis and Karagiannis (2018) start from this type of approach to additionally provide expressions both for the average intra-group composite indicator value as well as for a group's average intergroup composite indicator value, the former being a simple arithmetic mean of intragroup values and the latter a ratio of arithmetic averages of pooled and intra-group scores. Table 1 provides these aggregate scores for our regions using 2015 data. Intuitively, the numerical values of this (average) between group indicator can be considered as a measure of (average) shortfall of that group's best practice frontier to a common, pooled frontier.

For ease of comparison, the last column of Table 1 also reports the original HDI values for that year, as provided in UNDP (2016a, p. 205). It can be seen that the aggregate between-group effects are broadly in line with the ordering of regions according to these actual HDI values. Still, and recalling our findings for Qatar and the United Arab Emirates, for the Arab states there is an apparent difference, depending on whether one compares regional performances on the basis of regional averages (and a fixed weighting system), i.e. the official HDI values in the last column, or on the basis of their respective best practices (as generated by a BoD-model) as reported in the 'between groups' column. A similar remark can be made for the region Latin America and the Carribean, where Chile is an important regional best practice and has a composite HDI score relative to the pooled frontier of about $0.97 .{ }^{4}$

\footnotetext{
${ }^{4}$ As stated in the previous footnote, however, Chile is in fact simultaneously a (developing) OECD member and figures under the UNDP's Latin America and the Caribbean group.
} 
Table 1: Aggregate within and between group human development scores using the Karagiannis and Karagiannis (2018) formula, and HDI 2015 regional values as reported by UNDP (2016a)

\begin{tabular}{|c|c|c|c|}
\hline & Within group & Between groups & $\underline{\text { HDI (UNDP) }}$ \\
\hline OECD & 0.965 & 1.000 & 0.887 \\
\hline Arab States & 0.896 & 0.934 & 0.687 \\
\hline Asia and the Pacific & 0.904 & 0.860 & 0.720 \\
\hline Europe and Central Asia & 0.957 & 0.871 & 0.756 \\
\hline Latin America and the Carribean & 0.905 & 0.936 & 0.751 \\
\hline South Asia & 0.890 & 0.870 & 0.621 \\
\hline Sub-Saharan Africa & 0.751 & 0.848 & 0.523 \\
\hline
\end{tabular}

The alternative approach that we subsequently consider instead allows for direct bilateral and, by transitivity, multilateral comparisons between all groups, and was introduced in the literature by Asmild and Tam (2007). Its construction is fairly intuitive and again starts from program (1), but considers only the observations belong to one specific group as possible comparison partners. We henceforth use the notation $\theta_{o}^{g 1}$ for the composite indicator value as generated by a program similar to (1), but with only a subset $\sum_{i=1}^{I} w_{i 0} Y_{i j}^{g_{1}} \leq 1$ now constituting the $j=1, \ldots, \# g_{1}$ normalization constraints. Other indicator values $\theta_{o}^{g_{2}}, \theta_{o}^{g_{3}}, \ldots ., \theta_{o}^{g_{G}}$ and associated optimization problems are similarly defined.

Whereas the possible comparison countries are thus restricted to one specific group, this restriction does not apply to the evaluated observation itself. It is therefore e.g. possible that an evaluated country (which does not belong to the group $g_{j}$ defining the $\# g_{j}$ normalization constraints) ends up with a composite indicator value higher than one, given that its underlying data outperform the (aggregate) best practice within the group against which that specific country is being compared. To take but one example, still on the basis of 2015 data and using program (1)-(2): Australia's composite score is 1.27 relative to a best-practice frontier generated by Arab countries, and even 1.35 relative to a best-practice frontier generated by Sub-Saharan African countries. Note that this example provides 'local' evidence that the Arab best-practice frontier outperforms that of Sub-Saharan Africa. Ideally though, one would like to arrive at comparisons at an aggregate level. 
In fact, the Asmild-Tam Global Frontier Difference index is indeed global in the sense that it uses all $(n)$ observations to arrive at the following expression, providing an aggregate numerical value for the difference between, e.g., two groups $g_{1}$ and $g_{2}$ :

$$
\operatorname{GFI}\left(g_{1}, g_{2}\right)=\left(\frac{\prod_{k=1}^{n} \theta_{k}^{g_{1}}}{\prod_{k=1}^{n} \theta_{k}^{g_{2}}}\right)^{1 / n}=\prod_{k=1}^{n}\left(\frac{\theta_{k}^{g_{1}}}{\theta_{k}^{g_{2}}}\right)^{1 / n}
$$

The latter formulation immediately reveals that what varies is indeed the best practice frontier against which the relative performance of each observation is cast. If, on average, the $g_{1}$ group best practices outperform those of the $g_{2}$ group, this would imply that countries obtain a composite score $\theta_{k}^{g_{1}}$ which is, on average, lower than its counterpart $\theta_{k}^{g_{2}}$ (as they are assessed relative to a less demanding best practice set in the latter case). Accordingly, when $G F I\left(g_{1}, g_{2}\right)<1$ this indicates that the first group performs better, on average, than the second. States otherwise, the best practice frontier composed by the countries of group $g_{1}$ is positioned further away (read, comprises better human development data) than the best practice frontier determined by the countries belonging to group $g_{2}$. Note that it is important to be specific about the order of comparison here, as it follows from (3) that $\operatorname{GFI}\left(g_{1}, g_{2}\right)=\operatorname{GFI}\left(g_{2}, g_{1}\right)^{-1}$.

With an eye towards our empirical application, we further indicate that the Asmild-Tam index (3), given the use of a geometric mean, implies straightforward multilateral (chained) extensions

$$
\begin{aligned}
\operatorname{GFI}\left(g_{1}, g_{G}\right) & =\left(\frac{\prod_{k=1}^{n} \theta_{k}^{g_{1}}}{\prod_{k=1}^{n} \theta_{k}^{g_{2}}}\right)^{1 / n}\left(\frac{\prod_{k=1}^{n} \theta_{k}^{g_{2}}}{\prod_{k=1}^{n} \theta_{k}^{g_{3}}}\right)^{1 / n} \ldots\left(\frac{\prod_{k=1}^{n} \theta_{k}^{g_{G-1}}}{\prod_{k=1}^{n} \theta_{k}^{g_{G}}}\right)^{1 / n} \\
& =\prod_{k=1}^{n}\left(\frac{\theta_{k}^{g_{1}}}{\theta_{k}^{g_{2}}}\right)^{1 / n}\left(\frac{\theta_{k}^{g_{2}}}{\theta_{k}^{g_{3}}}\right)^{1 / n} \ldots\left(\frac{\theta_{k}^{g_{G-1}}}{\theta_{k}^{g_{G}}}\right)^{1 / n} \\
& =G F I\left(g_{1}, g_{2}\right) \times G F I\left(g_{2}, g_{3}\right) \times \ldots \times \operatorname{GFI}\left(g_{G-1}, g_{G}\right)
\end{aligned}
$$

Both (3) and (4) as well as the Australian example above also clearly reveal that the global difference between any pair of regions intentionally and partly builds on observations that do not belong to either one of the specific regional pair considered. But the contributions of each group to a pairwise (or chained) global frontier difference index can in fact be singled out easily. Starting from (3), for example, and still given $G$ groups, one can alternatively decompose the index as: 


$$
\operatorname{GFI}\left(g_{1}, g_{2}\right)=\left[\prod_{k \in g_{1}}\left(\frac{\theta_{k}^{g_{1}}}{\theta_{k}^{g_{2}}}\right) \times \prod_{k \in g_{2}}\left(\frac{\theta_{k}^{g_{1}}}{\theta_{k}^{g_{2}}}\right) \times \ldots \times \prod_{k \in g_{G}}\left(\frac{\theta_{k}^{g_{1}}}{\theta_{k}^{g_{2}}}\right)\right]^{1 / n}
$$

Now, if $G F I\left(g_{1}, g_{2} \mid g_{j}\right)$ is used to denote average difference between any two groups $g_{1}$ and $g_{2}$, on the basis of an assessment using data of group $j$ only, i.e. $G F I\left(g_{1}, g_{2} \mid g_{j}\right)=\prod_{k \in g_{j}}\left(\theta_{k}^{g_{1}} / \theta_{k}^{g_{2}}\right)^{1 / \# g_{j}}$, one can rewrite (3) as a weighted geometric average of these group assessments:

$$
\operatorname{GFI}\left(g_{1}, g_{2}\right)=\left(G F I\left(g_{1}, g_{2} \mid g_{1}\right)^{\# g_{1}} \times G F I\left(g_{1}, g_{2} \mid g_{2}\right)^{\# g_{2}} \times \ldots \times G F I\left(g_{1}, g_{2} \mid g_{G}\right)^{\# g_{G}}\right)^{1 / n}
$$

where $n=\Sigma_{j}\left(\# g_{j}\right)$.

It should furthermore be noted that this framework is also easily extendable to check for changes in aggregate intergroup differences over time. Assume for example that we have data on two groups $g_{1}$ and $g_{2}$ for two periods $s$ and $t$, with the corresponding period $s$ and period $t$ global frontier efficiency indices now being denoted as $\operatorname{GFI}\left(g_{1}, g_{1}, s\right)$ and $\operatorname{GFI}\left(g_{1}, g_{1}, t\right)$ respectively. We will use such indices in the next section to consequently look at measures of the kind

$$
\begin{aligned}
G F I\left(g_{1}, g_{2}, s, t\right) & =\frac{G F I\left(g_{1}, g_{2}, t\right)}{\operatorname{GFI}\left(g_{1}, g_{2}, s\right)} \\
& =\left(\frac{\prod_{k=1}^{n}\left(\theta_{k}^{t, g_{1}} / \theta_{k}^{t, g_{2}}\right)}{\prod_{k=1}^{n}\left(\theta_{k}^{s, g_{1}} / \theta_{k}^{s, g_{2}}\right)}\right)^{1 / n}=\left(\frac{\prod_{k=1}^{n}\left(\theta_{k}^{t, g_{1}} / \theta_{k}^{s, g_{1}}\right)}{\prod_{k=1}^{n}\left(\theta_{k}^{t, g_{2}} / \theta_{k}^{s, g_{2}}\right)}\right)^{1 / n}
\end{aligned}
$$

The last formula indicates the mathematically straightforward fact that the relative change in a pairwise global frontier difference index equals a pairwise global frontier difference index defined on group frontier changes, i.e. if we denote $\prod_{k=1}^{n}\left(\theta_{k}^{t, g_{1}} / \theta_{k}^{s, g_{1}}\right)^{1 / n}$ as $\operatorname{GFC}\left(g_{1}, s, t\right)$ we can rewrite (7) equivalently as

$$
\operatorname{GFI}\left(g_{1}, g_{2}, s, t\right)=\frac{G F C\left(g_{1}, s, t\right)}{G F C\left(g_{2}, s, t\right)}
$$

As already touched upon in the previous section, a concern when using the framework just sketched is that of group-size bias. To explain this concern in more detail consider for instance the difference between evaluating the human development performances of the $n$ countries in 
the sample relative to respectively East Asia and the Pacific best practice frontier and to the South Asian best practice frontier. In the former case this means that country performances are assessed relative to 24 countries, whereas in the second case only 9 countries serve as possible references. Obviously, this means that the probability for a country of getting a high BoDbased HDI-score is higher in the latter case (as then a country's human development performance data are, ceteris paribus, compared to a smaller group of peers). Precisely for this reason, resorting to the order- $m$ DEA model we described in the previous section allows for neutralizing the group bias concern, viz. by setting the $m$-value equal for all country groups (here, $m=5$ ), so that country composite HDI-scores are always compared to the same number of peers.

\section{An application to regional Human Development differences}

In this section we apply the global frontier difference index framework to assess the extent of interregional differences between BoD human development indices for the years 2010 and 2015. The regions we discern are those appearing in Figure 1, and the constituent data are a country's health, income and education index values for these two years. For both 2010 and 2015, each group of countries is compared to a best practice frontier that is determined by the countries of the different country groups and one best practice frontier that is determined by all countries in the data set (world frontier). Given that there are 7 country groups in the dataset, this means that $7+1$ best practice frontiers were estimated. In the estimations we use a robust version of the restricted BoD-program as in (1)-(2) (with parameters $m=5$ and $B=2,500$ runs) to generate all individual country scores.

Table 2 reports pairwise Global Frontier difference indices for the years 2010 and 2015 using formula (3). Specifically, the table is organized such that lines collect the first region (" $g_{1}$ ") which are compared with the other regions (" $g_{2}$ ") as listed in the columns. Given that $G F I\left(g_{1}, g_{2}\right)=G F I\left(g_{2}, g_{1}\right)^{-1}$ we only show halve of the possible pairwise comparisons. The first line thus shows, in both 2010 and 2015, that a country will get a lower composite value when compared with the OECD best practice frontier than when it is compared with the best practice frontier as created by any other region. Similarly, the last column reveals that SubSaharan Africa is globally outperformed by any other region in both years. 
These findings basically corroborate earlier information about both the best and worst performing regions as reported both in Figure 1 and Table 1. Put otherwise, the fundamental driver for these robust findings are not the exact methods used to establish the (country or regional) composite scores and interregional performance differences, but rather the underlying constituent data. This is also shown in Appendix 1, where we provide a three-dimensional scatter plot of the three index values that serve as our primitive variables, revealing both the dominance of the OECD data as well as the fact that Sub-Saharan African countries have constituent data situated mainly at the bottom of the sample.

Conversely though, there are instances in which methodological choices do have an impact on the inferences that could be drawn about interregional differences. We have already indicated (in Table 1) that the difference between the Arab region and Latin America and the Caribbean largely shrinks if one compares either of them relative to the pooled (world-wide) metafrontier rather than on account of their average HDI-values. Table 2 further shows that using the global frontier difference index indicates virtually no (best practice) difference between both regions.

We use decomposition (6) to provide additional analysis of their small intergroup difference, and notably focus on the observed GIF value of 1.006 for 2015 . The decomposition is detailed in Table 3. Recalling the formula $\operatorname{GFI}\left(g_{1}, g_{2} \mid g_{j}\right)=\prod_{k \in g_{j}}\left(\theta_{k}^{g_{1}} / \theta_{k}^{g_{2}}\right)^{1 / \# g_{j}}$, it is again the case that group 1 can be taken to be better performing than group 2 if, on average, the numerators in the foregoing expression are lower than the denominators or, equivalently, if $\operatorname{GFI}\left(g_{1}, g_{2} \mid g_{j}\right)<1$. Table 3 however reveals that, when applied to the Arab States and Latin America and the Caribbean, this result is actually dependent on the specific (regional) data used to establish this difference.

For example, when OECD countries are compared to either of the two frontiers, the Latin American and the Caribbean frontier seems closer to these OECD data than the one constituted by the Arab states' data, hence the Latin American and the Caribbean group performs relatively better when judged through this lens. Yet the opposite holds if one would assess this difference using e.g. the Sub-Saharan African countries as reference observations. In short, this mixed evidence conveys that both regions are de facto very similar at the aggregate level when it comes to their comparative frontier performance. 
Table 2: Global Frontier Human Development difference indices for world regions

\begin{tabular}{|c|c|c|c|c|c|c|}
\hline & \multicolumn{6}{|c|}{2010} \\
\hline Region & $\begin{array}{l}\text { vs. Arab } \\
\text { States }\end{array}$ & $\begin{array}{l}\text { vs. East } \\
\text { Asia \& } \\
\text { Pacific }\end{array}$ & $\begin{array}{l}\text { vs. Europe \& } \\
\text { Central Asia }\end{array}$ & $\begin{array}{l}\text { vs. Latin } \\
\text { America \& } \\
\text { Caribbean }\end{array}$ & vs. South Asia & $\begin{array}{c}\text { vs. Sub } \\
\text { Saharan } \\
\text { Africa }\end{array}$ \\
\hline OECD & 0.8729 & 0.8159 & 0.8456 & 0.8826 & 0.7721 & 0.7167 \\
\hline Arab States & & 0.9347 & 0.9687 & 1.0111 & 0.8845 & 0.8210 \\
\hline East Asia \& Pacific & & & 1.0364 & 1.0817 & 0.9463 & 0.8784 \\
\hline Europe \& Central Asia & & & & 1.0437 & 0.9131 & 0.8475 \\
\hline Latin America \& Caribbean & & & & & 0.8748 & 0.8120 \\
\hline \multirow[t]{2}{*}{ South Asia } & & & & & & 0.9282 \\
\hline & \multicolumn{6}{|c|}{2015} \\
\hline Region & $\begin{array}{l}\text { vs. Arab } \\
\text { States }\end{array}$ & $\begin{array}{l}\text { vs. East } \\
\text { Asia \& } \\
\text { Pacific }\end{array}$ & $\begin{array}{l}\text { vs. Europe \& } \\
\text { Central Asia }\end{array}$ & $\begin{array}{c}\text { vs. Latin } \\
\text { America \& } \\
\text { Caribbean }\end{array}$ & vs. South Asia & $\begin{array}{c}\text { vs. Sub } \\
\text { Saharan } \\
\text { Africa }\end{array}$ \\
\hline OECD & 0.8885 & 0.8431 & 0.8702 & 0.8938 & 0.8381 & 0.7608 \\
\hline Arab States & & 0.9490 & 0.9795 & 1.0060 & 0.9433 & 0.8563 \\
\hline East Asia \& Pacific & & & 1.0321 & 1.0610 & 0.9940 & 0.9024 \\
\hline Europe \& Central Asia & & & & 1.0271 & 0.9631 & 0.8743 \\
\hline Latin America \& Caribbean & & & & & 0.9377 & 0.8512 \\
\hline South Asia & & & & & & 0.9078 \\
\hline
\end{tabular}


Table 3: Decomposition of the Global Frontier difference index between the Arab Region and Latin America \& the Caribbean (2015 value)

\begin{tabular}{lccc}
\hline \hline & value & $\begin{array}{c}\left(\# g_{j} / n\right) \\
(\%)\end{array}$ & $G F I\left(g_{1}, g_{2} \mid g_{j}\right)^{\# g_{j} / n}$ \\
\hline GFI(Arab, Latin America| OECD) & 1.0210 & 17.7 & 1.0037 \\
GFI(Arab, Latin America| Arab states) & 0.9682 & 11.0 & 0.9964 \\
GFI(Arab, Latin America $\mid$ East Asia/Pacific) & 1.0185 & 13.3 & 1.0024 \\
GFI(Arab, Latin America| Europe \& Central Asia) & 1.0226 & 9.4 & 1.0021 \\
GFI(Arab, Latin America|Latin America \& the Caribbean) & 1.0105 & 18.2 & 1.0019 \\
GFI(Arab, Latin America|South Asia) & 1.0169 & 5.0 & 1.0008 \\
GFI(Arab, Latin America|Sub-Saharan Africa) & 0.9948 & 25.4 & 0.9987 \\
\hline \multicolumn{1}{c}{ GFI(Arab, Latin America) } & & $\mathbf{1 . 0 0 6 0}$ \\
\hline \hline
\end{tabular}

Finally, we also look at regional performance and frontier difference changes over time. Recalling expression (8), Table 4 provides the building blocks for assessing such changes by reporting $G F C\left(g_{j}, s, t\right)$ values for all groups (pairwise comparisons, i.e. the actual $G F I\left(g_{1}, g_{2}, s, t\right)$ values, are provided in Appendix 2).

Table 4: Global Frontier Difference Change (GFC) for country regions

\begin{tabular}{lc}
\hline \hline Region 2010 vs Region 2015 & GFC \\
\hline OECD & 1.0558 \\
Arab States & 1.0374 \\
East Asia \& Pacific & 1.0217 \\
European \& Central Asia & 1.0260 \\
Latin America \& the Caribbean & 1.0426 \\
South Asia 2010 & 0.9727 \\
Sub Saharan African & 0.9946 \\
\hline \hline
\end{tabular}

Table 4 thus again reveals some differences with the analysis on the basis of average regional values, as reported in Figure 1. While both indicate some progress for most regions, Figure 1 indicates that (on average) also the least developed regions have progressed. Table 4, on the 
other hand, complements this finding with the result that regional best practices seemed to stay unaltered or even slightly deteriorated in Sub-Saharan Africa and South Asia between 2010 and 2015. Table 4 further shows that it was actually the OECD group that advanced most in that same period, followed by Latin America and the Caribbean. Accordingly, these findings imply an increased gap between the most and least developed regions, as is further documented in the Appendix 2.

\section{Conclusions}

The determination of (best-practice) benchmarks is a defining feature of the majority of DEAmodels, and, hence, of the BoD-approach to composite indicator construction that derives from such models. This feature sometimes requires to make ex ante choices regarding possible natural candidates for being such benchmarks, a case in point in the specific context of this paper being the one where observations are grouped on the basis of some geographical criterion (although this is certainly not the only possibility; Karagiannis \& Karagiannis (2018) consider an application where financial composite indicators are constructed and hospitals are grouped according to their ownership status). In turn, imposing such a group structure leads quite naturally to questions regarding possible systematic differences between these groups.

Examining composite indicators at such an aggregate, group level is one way to deal with the concern that individual country scores and rankings could well be volatile in the sense of depending too much on the specific way they are constructed. But this is of course no guarantee for robust results. Our application to human development data does reveal that some groups of countries can be consistently better performers whereas others are consistently lagging behind other groups, broadly regardless of the exact construction and comparison methods used to assess this difference. Quite naturally, such strong results ultimately are based on the underlying differences in the composite indicators' constituent data. Yet in other cases intergroup differences, or the evolution of such differences over time, may appear larger or smaller, or even non-existent depending on the specific way they are assessed. It should however be noted that this may well lead to complementary rather than conflicting findings. Think e.g. of the catching up of the Sub Saharan African region relative to others between 2010 and 2015 when performance is gauged by regional HDI averages, which goes hand in hand with the observation that in terms of regional best practices this region has actually lost some ground over the same period. 
While we have reported on interregional differences using both the metafrontier method as introduced in a BoD setting by Karagiannis and Karagiannis (2018) and the Asmild-Tam global frontier difference index, we have here predominantly focused on the latter and leave a thorough comparison of each method's relative pros and cons as a suggestion for further research. Unlike in our specific case, where a pooled (world-wide) group of benchmarks does not appear that implausible, there may be settings in which (the construction of) a metafrontier, necessary for assessing between-group differences when using the 'program efficiency' approach, but creating the possibility that in such a setting an observation is compared to a linear combination of observations that each belong to different groups, may be less acceptable. From that perspective, the global frontier difference index appears to provide a more direct way for comparing group frontiers, and the fact that all observations in the dataset are used to estimate the extent of the difference between two groups can be taken as embedding a concern for providing a more accurate estimate of the frontier difference (Asmild, 2015). Still, recalling Table 1, the (average) intergroup composite indicator that constitutes part of the "program efficiency' decomposition is as such not a part of the global frontier difference index, but can provide valuable complementary information in its own right.

Finally, we recall that we have chosen here to illustrate the possible use of the global frontier difference index, combined with the BoD-approach to composite indicator construction, on the basis of one specific (admittedly robust order-m) model. We recall however that this basic model can be easily extended with common weighting structures (e.g. applying to a specific regional group only), can be recast as a multiplicative or weight minimizing model, etc. 


\section{References}

Aguña, C. G., \& Kovacevic, M. (2010). Uncertainty and sensitivity analysis of the human development index. Human Development Research Paper, 47.

Andersen, P., \& Petersen, N. C. (1993). A procedure for ranking efficient units in data envelopment analysis. Management Science, 39(10), 1261-1264.

Asmild, M. (2015). Frontier differences and the global Malmquist index. In Data Envelopment Analysis (pp. 447-461). Springer US.

Asmild, M., \& Tam, F. (2007). Estimating global frontier shifts and global Malmquist indices. Journal of Productivity Analysis, 27(2), 137-148.

Banker, R. D., \& Chang, H. (2006). The super-efficiency procedure for outlier identification, not for ranking efficient units. European Journal of Operational Research, 175(2), 13111320 .

Banker, R. D., \& Gifford, J. L. (1988). A relative efficiency model for the evaluation of public health nurse productivity. Pittsburgh: Carnegie Mellon University.

Bougnol, M.-L., Dulá, J. H., Estellita Lins, M. P., \& Moreira da Silva, A. C. (2010). Enhancing standard performance practices with DEA. Omega, 38, 33-45.

Cazals, C., Florens, J. P., \& Simar, L. (2002). Nonparametric frontier estimation: a robust approach. Journal of Econometrics, 106(1), 1-25.

Charnes, A., Cooper, W. W., \& Rhodes, E. (1981). Evaluating program and managerial efficiency: an application of data envelopment analysis to program follow through. Management Science, 27(6), 668-697.

Cherchye, L., Moesen, W., Rogge, N., \& Van Puyenbroeck, T. (2007). An introduction to 'benefit of the doubt' composite indicators. Social Indicators Research, 82(1), 111-145.

Cherchye, L., Ooghe, E., \& Van Puyenbroeck, T. (2008). Robust human development rankings. The Journal of Economic Inequality, 6(4), 287-321.

Chowdhury, S., \& Squire, L. (2006). Setting weights for aggregate indices: An application to the commitment to development index and human development index. The Journal of Development Studies, 42(5), 761-771.

Crafts, N. (2002). The human development index, 1870-1999: Some revised estimates. European Review of Economic History, 6(3), 395-405.

Conte, L., Della Torre, G., \& Vasta, M. (2007). The human development index in historical perspective: Italy from political unification to the present day (No. 491). Department of Economics, University of Siena.

Daraio C, Simar L (2007) Advanced robust and nonparametric methods in efficiency analysis: methodology and applications. Series: Studies in Productivity and Efficiency. Springer, New York

Despotis, D. K. (2005a). A reassessment of the human development index via data envelopment analysis. Journal of the Operational Research Society, 56(8), 969-980. 
Despotis, D. K. (2005b). Measuring human development via data envelopment analysis: the case of Asia and the Pacific. Omega, 33(5), 385-390.

Foster, J. E., McGillivray, M., \& Seth, S. (2013). Composite indices: Rank robustness, statistical association, and redundancy. Econometric Reviews, 32(1), 35-56.

Hardeman, S. \& Dijkstra, L. (2014). The EU Regional Human Development Index, Ispra: Joint Research Centre. JRC Science and Policy Report EUR 26817.

Harttgen, K., \& Klasen, S. (2012). A household-based human development index. World Development, 40(5), 878-899.

Hirai T. (2017). The Human Development Index and Its Evolution. In: The Creation of the Human Development Approach. Palgrave Macmillan, Cham.

Hou, J., Walsh, P. P., \& Zhang, J. (2015). The dynamics of human development index. The Social Science Journal, 52(3), 331-347.

Høyland, B., Moene, K., \& Willumsen, F. (2012). The tyranny of international index rankings. Journal of Development Economics, 97(1), 1-14.

Karagiannis, R., \& Karagiannis, G. (2018). Intra- and inter-group composite indicators using the BoD model, Socio-Economic Planning Sciences, 61, 44-51.

Lai, D. (2003). Principal component analysis on human development indicators of China. Social Indicators Research, 61(3), 319-330.

Mahlberg, B., \& Obersteiner, M. (2001). Remeasuring the HDI by data envelopement analysis. International Institute for Applied Systems Analysis Interim Report 01-069.

Mariano, E. B., Sobreiro, V. A., \& do Nascimento Rebelatto, D. A. (2015). Human development and data envelopment analysis: A structured literature review. Omega, 54, 33-49.

Martin, J.C., \& Mendoza, C.A., (2013). A DEA Approach to measure the quality-of-life in the municipalities of the Canary Islands. Social Indicators Research, 113(1), 335-353.

Morse, S. (2003). Greening the United Nations' human development index?. Sustainable Development, 11(4), 183-198.

Nardo, M., Saisana, M., Saltelli, A., Tarantola, S., Hoffman, A., \& Giovannini, E. (2005). Handbook on Constructing Composite Indicators.

Noorbakhsh, F. (1998). A modified human development index. World Development, 26(3), 517-528.

O’Donnell, C. J., Rao, D. P., \& Battese, G. E. (2008). Metafrontier frameworks for the study of firm-level efficiencies and technology ratios. Empirical Economics, 34(2), 231-255.

Permanyer, I. (2011). Assessing the robustness of composite indices rankings. Review of Income and Wealth, 57(2), 306-326.

Qizilbash, M. (1997). Pluralism and Well-Being Indices. World Development, 25, 2009-2026.

Ravallion, M. (2012). Troubling tradeoffs in the human development index. Journal of Development Economics, 99(2), 201-209. 
Staat, M. (2001). The effect of sample size on the mean efficiency in DEA: Comment. Journal of Productivity Analysis, 15(2), 129-137.

Staat, M. (2006). Bootstrap results for a measure of market efficiency. International Journal of Business Performance Management, 8(4), 328-343.

UNDP (2015). Human Development Report 2015: Work for Human Development. Available at: http://hdr.undp.org/sites/default/files/2015_human_development_report.pdf

UNDP (2016a). Human Development Report 2016: Human Development for Everyone. Available at: http://hdr.undp.org/sites/default/files/2016_human_development_report.pdf

UNDP (2016b). Technical notes 1-5. In: Human Development Report 2016: Human Development for Everyone. hdr.UNDP.org [online]. http://hdr.undp.org/sites/default/files/hdr2016_technical_notes.pdf

Van Puyenbroeck T. (2017). On the Output Orientation of the Benefit-of-the-Doubt Model. Social Indicators Research. https://doi.org/10.1007/s11205-017-1734-X 
Appendix 1: Scatter plots of constituent health, income and education index data

The two figures below show values of the life expectancy, education and income indices for all countries of the sample. These indices are constructed using the method outline in UNDP (2016). Black dots (high combined values) refer to OECD data, yellow dots to data for Sub-Saharan African countries

Figure A.1: Human Development Index sub-dimension data (year 2010 vs. year 2015)
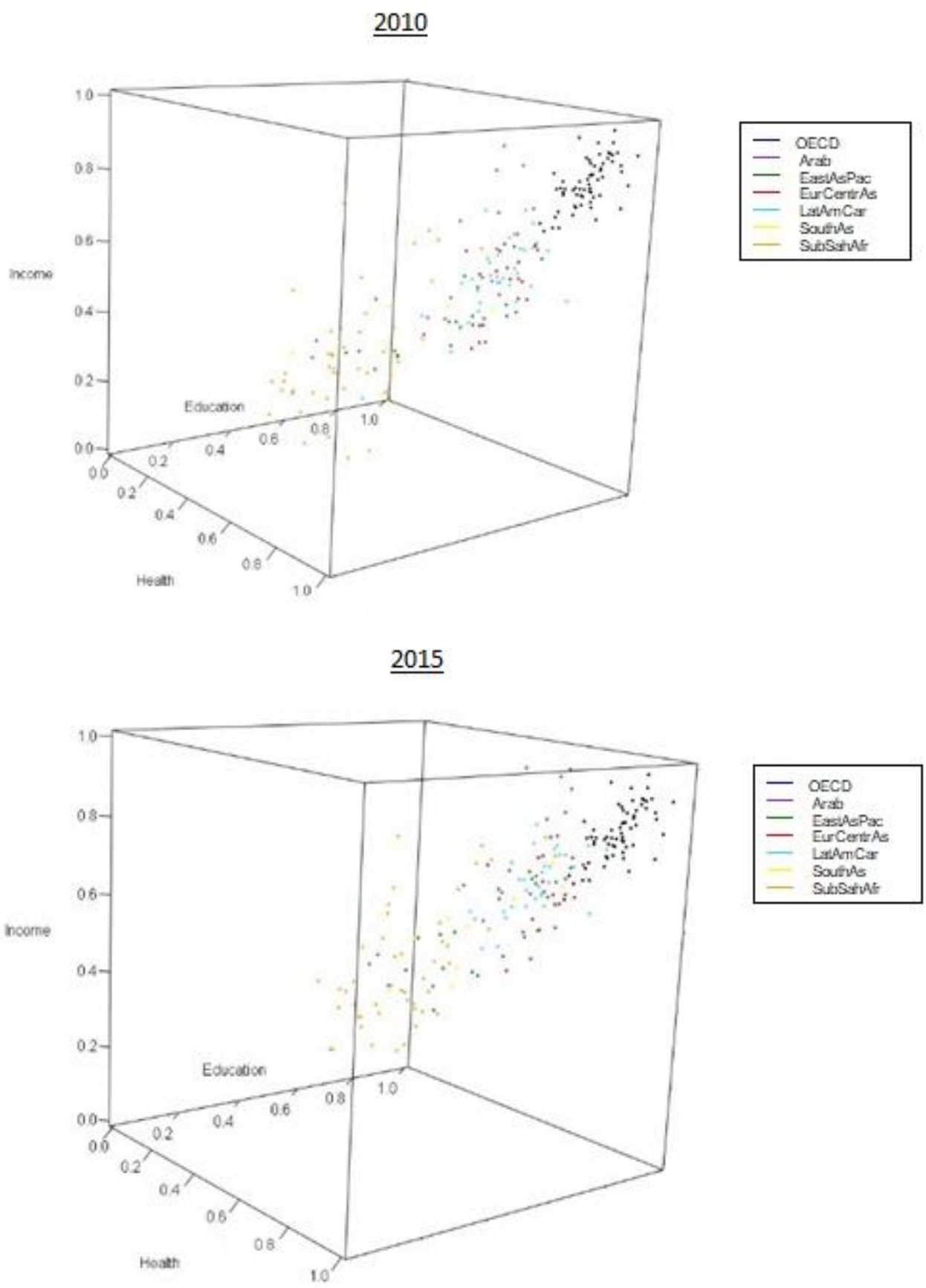
Appendix 2: Global frontier difference changes between 2010 and 2015

This table provides pairwise comparisons of frontier changes using expression (7). A value larger [smaller] than 1 indicates that the region mentioned at the left of the table has experienced a more [less] favorable frontier shift than the corresponding region mentioned on top of the column.

\begin{tabular}{|c|c|c|c|c|c|c|}
\hline \multirow[b]{2}{*}{ Region } & \multicolumn{6}{|c|}{$G F I\left(g_{1}, g_{2}, 2010,2015\right)$} \\
\hline & $\begin{array}{l}\text { vs. Arab } \\
\text { States }\end{array}$ & $\begin{array}{l}\text { vs. East } \\
\text { Asia \& } \\
\text { Pacific }\end{array}$ & $\begin{array}{l}\text { vs. Europe \& } \\
\text { Central Asia }\end{array}$ & $\begin{array}{c}\text { vs. Latin } \\
\text { America \& } \\
\text { Caribbean }\end{array}$ & vs. South Asia & $\begin{array}{c}\text { vs. Sub } \\
\text { Saharan } \\
\text { Africa }\end{array}$ \\
\hline OECD & 1.0178 & 1.0334 & 1.0291 & 1.0127 & 1.0855 & 1.0616 \\
\hline Arab States & & 1.0153 & 1.0111 & 0.9950 & 1.0665 & 1.0430 \\
\hline East Asia \& Pacific & & & 0.9959 & 0.9800 & 1.0504 & 1.0273 \\
\hline Europe \& Central Asia & & & & 0.9840 & 1.0548 & 1.0316 \\
\hline Latin America \& Caribbean & & & & & 1.0719 & 1.0483 \\
\hline South Asia & & & & & & 0.9780 \\
\hline
\end{tabular}

